\title{
Los Hongos en la salud y la enfermedad. Parte I.
}

\author{
Fungi in health and disease. Part I.
}

Ocara, Miranda ${ }^{1}$, Vieille, Peggy ${ }^{2}$, Carvajal, Laura ${ }^{2}$, Cruz, Rodrigo ${ }^{2 *}$

${ }^{1}$ Alumna de Medicina Universidad de Valparaíso.

${ }^{2}$ Laboratorio de Micología Universidad de Valparaíso.

*Autor para correspondencia: rodrigo.cruz@uv.cl

RECIBIDO: 01 de Diciembre de 2018

APROBADO: 01 de Enero de 2019

DOI: $10.22370 /$ bolmicol.2018.33.2.1370

LOS AUTORES DECLARAN NO TENER CONFLICTO DE INTERESES

Palabras claves: hongos, salud, enfermedad.

Key words: fungi, health, disease.

\section{RESUMEN}

Los hongos son organismos eucariontes que tienen nutrición absortiva, con presencia en los más variados ambientes y sustratos. Han sido parte de la historia del hombre y su desarro1lo, siendo útiles tanto en la alimentación como en la medicina, producción de enzimas, actividad industrial y silvicultura. Sin embargo, también tienen la capacidad de producir infecciones superficiales y profundas en humanos y animales, contaminar e infectar granos, frutas, plantas y generar verdaderos desastres ecológicos.

\section{INTRODUCCIÓN}

Los hongos son organismos eucariontes que inicialmente fueron clasificados en el reino vegetal. Whittaker en 1969 clasificó la vida en 5 reinos, donde los hongos constituyeron uno de ellos $(1,2)$. Posteriormente, en 1977, Woese creó el sistema de dominios y reinos, donde los hongos se incorporaron al dominio Eukarya y al reino Fungi, sin embargo, los micólogos han seguido es-

\begin{abstract}
Fungi are eukaryotic organisms, its nutrition is absorptive and they are widespread present in environment and substrates. They have been part of the history of human being and his development: they are useful as food, in medicine, enzyme production, in the industrial activity and forestry. However they have the capacity of infect superficial and deep human and animal tissues, contaminate and infect grains, fruits, plants and even produce environmental disasters.

tudiando a un conjunto de especies que se encuentran agrupadas en los reinos Fungi, Chromistas y Protozoos $(1,2)$.

Los hongos poseen, al igual que todos los eucariontes, células con una membrana lipídica, un citoplasma, un núcleo y otros organelos rodeados de membrana, además de una pared que está constituida por polisacáridos (glucanos, quitina, quitosán, mananos), proteínas y lípidos $(1,3)$.
\end{abstract}


Necesitan carbohidratos para obtener energía, ya que son heterótrofos, es decir no realizan fotosíntesis ni pueden fijar el carbono. La mayoría de los hongos tiene nutrición absortiva, es decir obtienen los nutrientes absorbiéndolos luego de la degradación de compuestos por enzimas que liberan al medio donde se encuentran, lo que les permite utilizar una variada cantidad de sustratos $(1,3)$.

La mayoría de las especies de este reino son aerobios estrictos, no son móviles, pueden ser unicelulares como las levaduras o multinucleares como los hongos filamentosos, los cuales están constituidos por hifas, cuyo conjunto se denominan micelio (imágenes 1 y 2) (3). Los hongos filamentosos superiores presentan septos regulares en las hifas (crecimiento centrípeto de la pared), las cuales a su vez pueden ser hialinas (por ejemplo, el género Aspergillus) o dematiáceas (por ejemplo, el género Alternaria) que presentan melanina en su pared (imagen 3) $(3,4)$. El septo simple se encuentra en las hifas de los Ascomycota y en los anamorfos (asexuales) de Ascomycota, caracterizándose por presentar una abertura con unas estructuras proteicas que regulan el paso entre los compartimentos, los cuerpos de Woronin (1). El doliporo se presenta principalmente en hongos del filo Basidiomycota, y se caracteriza por presentar a ambos lados de la abertura del septo, membranas continuas con el retículo endoplásmico, el parentosoma (1).

Los hongos inferiores presentan hifas sin septos o cenocíticas (por ejemplo, el género $R h i$ zopus), lo que le confiere una mayor tasa de crecimiento y un peor pronóstico a aquellos pacientes que sufren una infección invasora por estos (imagen 4 y 5) (4).

Las levaduras se reproducen principalmente a través de la gemación, pueden formar pseudomicelio y en algunas ocasiones micelio verdadero. Estas estructuras son importantes tanto en la adherencia como en la invasividad, principalmente en el género Candida (imagen 6) (5).

Existen algunos hongos que son dimórficos, pues cuando se encuentran en el ambiente a temperaturas bajo $37^{\circ} \mathrm{C}$ se encuentran en su estado filamentoso, pero cuando crecen a temperaturas de $37^{\circ} \mathrm{C}$ o más, se encuentran en su estado levaduriforme; es lo que sucede cuando estos hongos infectan a los humanos, animales o se siembran en el laboratorio en medios líquidos a las temperaturas señaladas (imagen 7 y 8) (6).

La distribución de los hongos es en general cosmopolita, encontrándose en los más variados
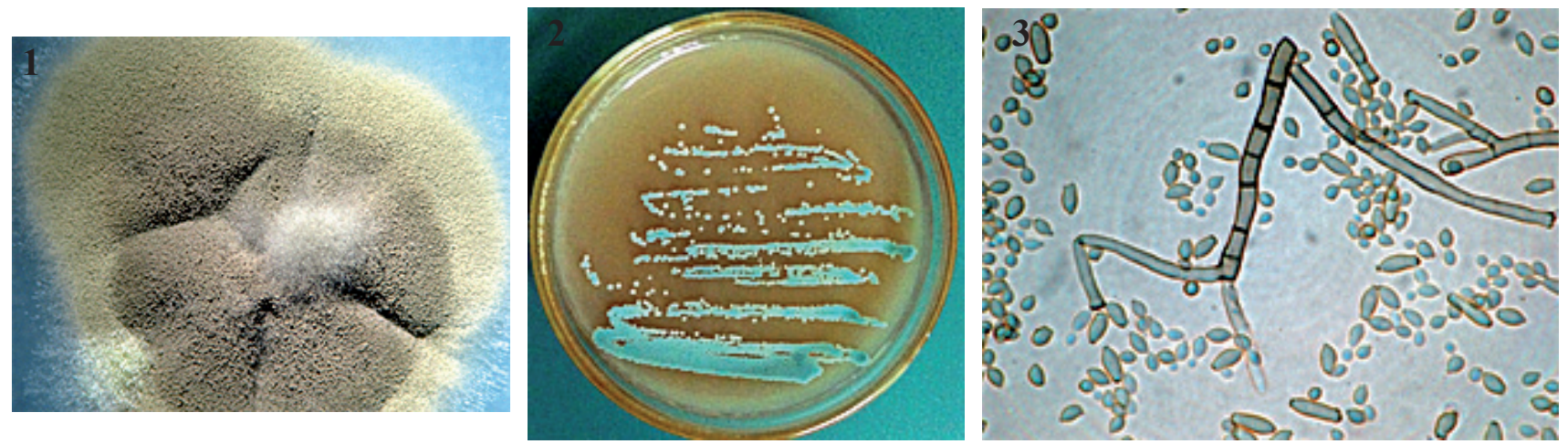

Imagen 1. Colonia de Cladosporium cladosporoides, hongo filamentoso dematiáceo.

Imagen 2. Colonias de levadura Candida albicans en medio cromogénico a los 5 días de cultivo a $37^{\circ} \mathrm{C}$. Imagen 3. Hifas con septos regulares en un hongo dematiáceo. Tinción Lactofenol con azul de algodón 100X. 

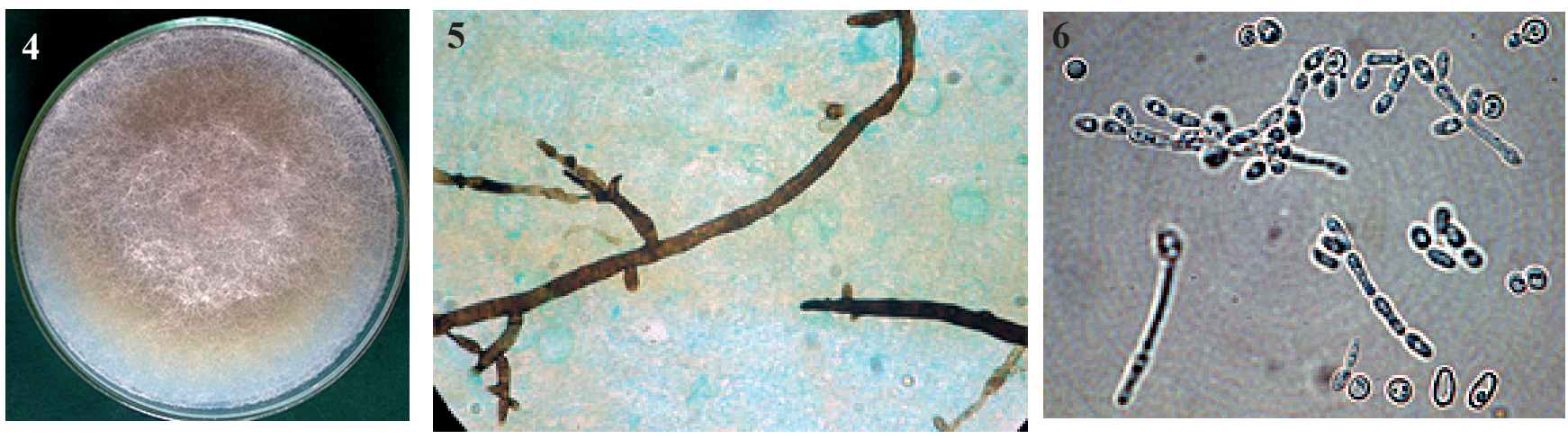

Imagen 4. Colonia de hongo inferior que creció rápidamente en 48 en agar Sabouraud a $37^{\circ} \mathrm{C}$.

Imagen 5. Hifas cenocíticas de un hongo inferior que provocó infección pulmonar en una paciente inmunocomprometida. Tinción Gomori-Grocott. 100 X.

Imagen 6. Levaduras de Candida albicans con gemación y pseudomicelio. Tinción Lactofenol con azul de algodón. $100 \mathrm{X}$.

sustratos; agua dulce y salada, tierra, madera viva o en descomposición, restos vegetales y animales, excrementos etc., y en los distintos climas; tropical, desiertos, estepa, frio extremo etc. Sin embargo, algunas especies se consideran endémicas de ciertos lugares, donde se han adaptado a las condiciones climáticas, hábitat específico o a la presencia de algún hospedero $(1,7)$.

Dependiendo de los mecanismos de patogenicidad que presenten, tanto hongos filamentosos como levaduras pueden provocar infecciones

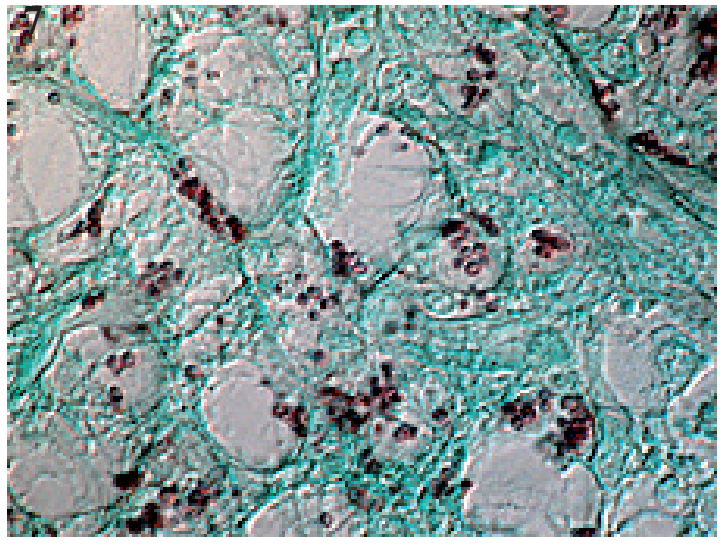

superficiales o profundas en plantas, animales y ser humano, determinando en ocasiones la muerte del huésped (7).

Durante su vida los hongos pueden presentar 2 tipos de reproducción: asexual y sexual. Algunos pueden hacer ambas, mientras otros solo una de ellas. La reproducción asexual favorece principalmente la distribución, mientras que la sexual la variabilidad genética y por lo tanto la adaptación a cambios del ambiente donde se desarrollan las especies (8).

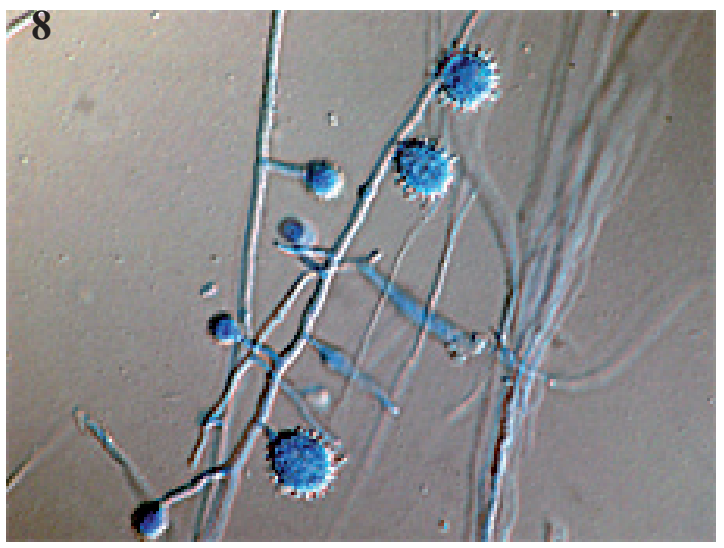

Imagen 7. Levaduras de un hongo dimórfico en una adenopatía cervical de un paciente con histoplasmosis diseminada. Tinción de gomori-Grocott. $100 \mathrm{X}$.

Imagen 8. Macroconidios denticulados de Histoplasma capsulatum en cultivo a $32^{\circ} \mathrm{C}$. Tinción de Lactofenol con azul de algodón. $100 \mathrm{X}$. 


\section{HONGOS ÚTILES PARA EL HUMANO}

Las múltiples características de los hongos hacen que tengan tanto propiedades beneficiosas como perjudiciales para el ser humano. Dentro de las utilidades, podemos encontrar variados usos, en la medicina, la industria alimenticia, la agricultura, e incluso la industria textil (9).

Es conocida la historia de Alexander Fleming en su laboratorio, quien notó en un cultivo de Staphylococcus aureus la inhibición de su crecimiento por un hongo filamentoso, Penicillium chrysogenum, dando paso a uno de los grandes hitos en la medicina contemporánea: los antibióticos (10). Otro ejemplo son las cefalosporinas, las cuales provienen del género Cephalosporium-Acremonium, siendo estos compuestos imprescindibles para la medicina como la conocemos hoy en día (11).

Por su parte, en la industria alimenticia los hongos cumplen diversos roles, sirviendo como apoyo para la producción de alimentos o ser un alimento en sí, como el típico Agaricus bisporus. ¿Que sería del pan y la cerveza sin levadura?, $S a$ ccharomyces cerevisiae es responsable de la fermentación de cerveza, sidra, vino y pan, entre otros alimentos (12). ¿Qué sería del queso sin hongos para producir particulares sabores? Penicillium roqueforti permite la maduración del queso roquefort, así como Penicillium camemberti del queso camembert (13).

Por otra parte, las micorrizas corresponden a una relación simbiótica entre un hongo y las raíces de una planta, por su asociación y efecto de absorción de nutrientes se utilizan en la agricultura para potenciar el desarrollo vegetal, además de proteger a las plantas de patógenos o aliviar la contaminación del suelo degradando sustancias tóxicas, permitiendo así la reducción del uso de fertilizantes y pesticidas (14).
Últimamente los estudios se han enfocado en encontrar otras propiedades para nuevos usos. Por ejemplo, en la industria textil se ha establecido la utilidad de algunos hongos para decolorar tintes industriales, lo cual no solo es útil para la manufactura, sino que también podría aplicarse en descontaminar aguas que suelen verse afectadas en los procesos de producción (15).
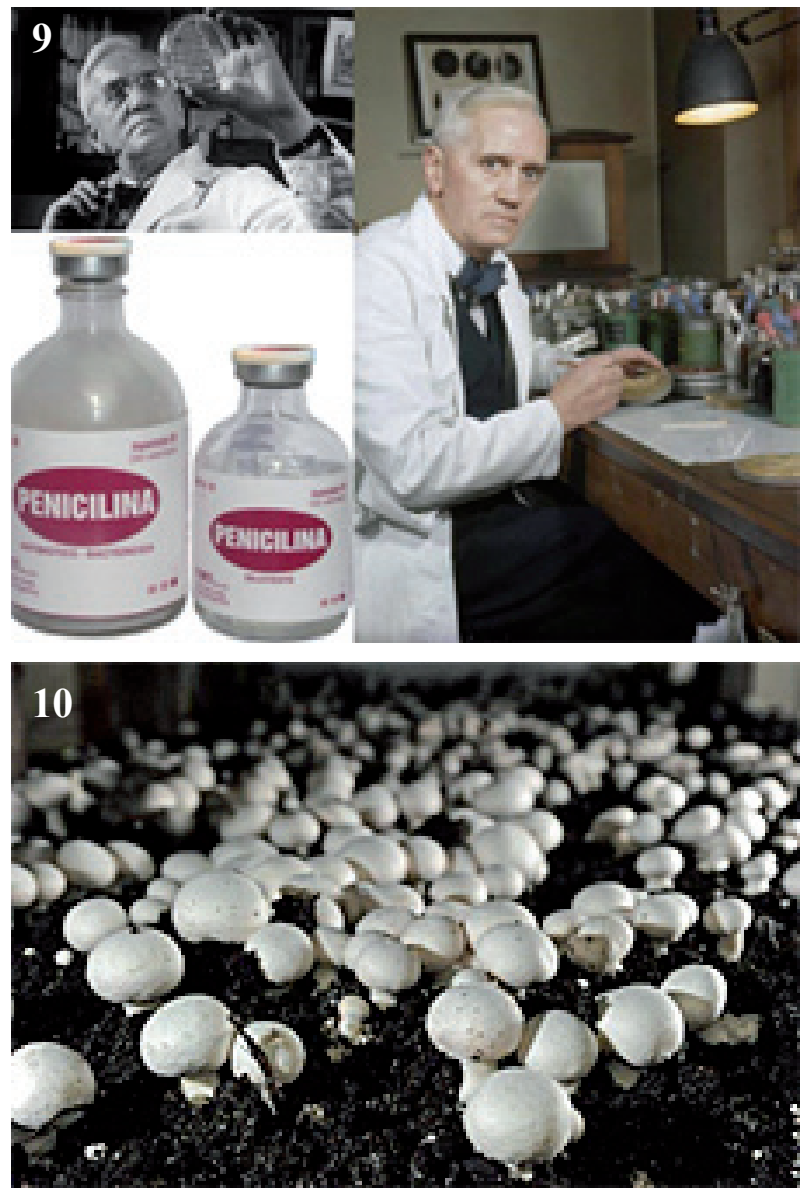

Imagen 9. Se observa a Alexander Fleming en su laboratorio de trabajo y la penicilina que luego se obtuvo de Penicillium chrysogenum. (obtenido de https://www.biografiasyvidas.com/monografia/fleming/penicilina.htm) .

Imagen 10. Se observa Agaricus bisporus. (obtenido de https://www.indiamart.com/proddetail/spawn-of-agaricus-bisporus-button-mushroom-17165317855.html) 
Los Hongos en la salud y la enfermedad. Parte I. - Ocara M.

\section{DESASTRES ECOLÓGICOS PROVOCADOS POR HONGOS}

Las plagas de los cultivos son conocidas desde los albores de la agricultura y es sabido que los hongos han sido causantes de enfermedades diseminadas en muchas especies vegetales, al nivel de alterar incluso el curso de la historia humana $(16,17,19)$. Un desastre se categoriza como una "Disrupción grave del funcionamiento de una comunidad o sociedad en cualquier escala" (18) y algunos de los desastres producidos por hongos (incluidos los oomycetes) condujeron a sociedades a la ruina económica, como en el caso del tizón tardío de la papa durante la hambruna irlandesa en el siglo XIX (17). La amenaza de enfermedades fúngicas lejos de disminuir, se ha visto reforzada por ciertas prácticas agrícolas y mediante la adaptación microbiana a nuevos ecosistemas, provocada por el comercio, el transporte y por el cambio climático. Una de las mayores pérdidas de biodiversidad hasta ahora documentada, fue causada por el hongo Batrachochytrium dendrobatidis descubierto en 1997, con la capacidad de infectar a más de 500 especies de anfibios (19).

Algunas especies que pueden afectar a plantas, árboles y animales son:

Phytophthora infestans (Oomycota) fue el causante de la hambruna que mató o desplazó a un cuarto de la población irlandesa en el siglo XIX (1845). Conocida como el tizón de la patata, se propagó desde Irlanda hacia Bélgica, Francia, los Países Bajos y luego en toda Europa Occidental. En Irlanda, destruyó el principal alimento básico de una población empobrecida en el contexto de la Revolución Industrial $(20,21)$.

Puccinia graminis (Basidiomycota) es el causante de la roya del trigo. La roya del tallo ha sido históricamente una importante enfermedad del trigo en los 5 continentes y se estima que ha producido pérdidas en el rendimiento mundial de trigo del orden de 6.2 millones de toneladas anuales durante el período 1961-2009 (20).

El tizón de la espiga del trigo y la cebada por Fusarium (Ascomycota) es una enfermedad importante en muchas áreas productoras, también se le conoce como "costra" y puede llegar a ser devastadora. Entre las especies de Fusarium que causan el tizón, F. graminearum es el patógeno predominante. Esta especie, además, puede producir la micotoxina deoxynivalenol (DON, comúnmente conocida como vomitoxina) en granos contamina$\operatorname{dos}(22)$.

Moniliophthora roreri (Basidiomycota) es el agente causal de la moniliasis del cacao o podredumbre acuosa de la cápsula del cacao. La infección inicial es asintomática, la cual persiste durante 3 meses hasta que las vainas se necrosan rápidamente, produciendo masas de esporas sobre su superficie. Los brotes más graves han llevado al abandono de cultivos de cacao en extensas áreas de Perú, Costa Rica, Colombia y México (23).

Las pérdidas anuales causadas por Magnaporthe oryzae (Ascomycota) causante de la piriculariosis en el arroz, varían entre el $10 \%$ y el $30 \%$ de la cosecha. En países como China, India, Pakistán $\mathrm{y}$ otras regiones altamente pobladas, dependen del arroz como alimento principal por lo que incluso pérdidas del $10 \%$ son significativas considerando que es suficiente para alimentar a 60 millones de personas durante un año (24).

El castaño americano, Castanea dentata, fue un componente esencial del ecosistema forestal del este de los Estados Unidos y era considerado el mejor castaño del mundo antes de que la especie fuera devastada por el tizón del castaño. Las comunidades rurales dependían de la cosecha de las castañas y la industria de la madera de castaño era un sector importante de las economías rurales. 
Cryphonectria parasitica es un ascomycete originario del este de Asia, que fue importado accidentalmente a los EE. UU a principios del siglo XX y que para mediados de siglo ya había eliminado al castaño americano como un árbol forestal maduro (25).

La Muerte Súbita del Roble es una enfermedad letal causada por Phytophthora ramorum (Oomycota). Se estima que el hongo se introdujo en California en la década de 1990 de forma involuntaria cuando plantas ornamentales infectadas, como los rododendros y las camelias fueron plantadas en el medio ambiente (26).

La infección fúngica que ha producido la mayor pérdida de biodiversidad causada por enfermedades, hasta el momento documentada, es debida al chytridiomycete Batrachochytrium dendrobatidis. Es capaz de infectar más de 500 especies de anfibios en todos los continentes. Como consecuencia de la infección, algunas áreas de América Central han perdido más del $40 \%$ de sus especies de anfibios, una pérdida que se ha traducido en cambios importantes a nivel de ecosistema (19).

El género Saprolegnia (Oomycota) produce micosis en peces de agua dulce, siendo el principal agente encontrado Saprolegnia parasitica produciendo infección primaria y oportunista. También se encuentra con alta frecuencia como agente de enfermedad en pisciculturas de salmonídeos (27).

El síndrome de la nariz blanca se asocia a un evento de mortalidad de murciélagos sin precedentes en el noreste de los Estados Unidos observado durante un censo rutinario de murciélagos en el 2006. La piel de los murciélagos afectados estaba colonizada por un hongo filogenéticamente relacionado con Geomyces spp. Los estudios han demostrado que la especie Pseudogymnoascus destructans (Ascomycota) es el agente causal del síndrome (19).
Durante las últimas dos décadas se han reportado un número sin precedentes de hongos patógenos nuevos y emergentes, así como también variantes de los ya existentes que causan enfermedades graves y mortalidad en diversos taxa, por ejemplo: en los corales blandos la aspergilosis de abanico de mar causada por Aspergillus sydowii, en las abejas el trastorno de colapso de colonias asociado con Nosema sp., y como patógenos humanos y de la vida silvestre en regiones previamente no endémicas se encuentra Cryptococcus gattii VGII en el distintas regiones de America $(17,19)$.

\section{INFECCIONES SUPERFICIALES EN HUMANOS}

Las dermatomicosis son infecciones superficiales causadas por hongos en tejidos queratinizados (piel y anexos) con prevalencias y formas clínicas que pueden variar según el país o región $(28,30)$. A pesar de ser conocidas ampliamente en el ámbito clínico, continúan siendo un tema constante de publicaciones nacionales y extranjeras.

Los principales agentes etiológicos son los dermatofitos (patógenos primarios que degradan y digieren la queratina) seguido de otros hongos considerados saprófitos u oportunistas que pueden causar infecciones o sobreinfecciones en piel, uñas o pelo (30).

Los dermatofitos pertenecen al grupo más antiguo de microorganismos que han sido reconocidos como agentes de enfermedades de humanos. Actualmente, son 9 los géneros que comprenden este grupo con más de 50 especies: Trichophyton (16 especies), Epidermophyton (1 especie), Nannizzia (9 especies), Microsporum (3 especies), Lophophyton (1 especie), Arthroderma (21 especies), Ctenomyces (1 especie), Paraphyton (3 especies) y Guarromyces gen.nov. (1 especie). Cada especie tiene un solo nombre válido y para las especies "borderline" aún son necesarios estudios más 

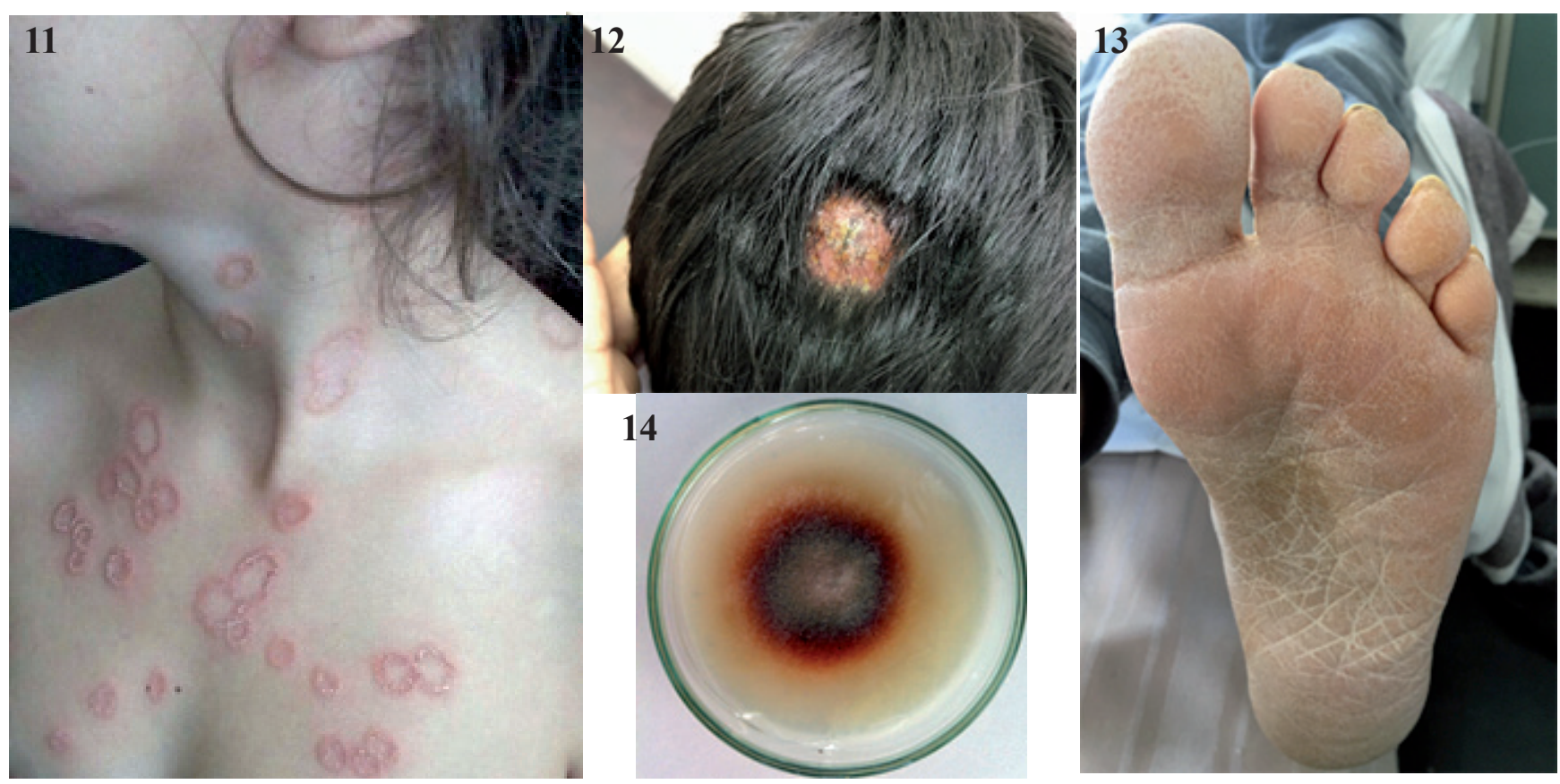

Imagen 11. Tiña corporis. Se observa lesiones redondeadas con borde eritematoso y solevantado en niña de 11 años de edad.

Imagen 12. Tiña capitis. Lesión redondeada, eritematosa, con pérdida y fractura de pelos en niño de 7 años de edad.

Imagen 13. Tiña pedis. Se observa descamación en toda la planta del pie. Paciente de 40 años de edad. Imagen 14. Colonia de Trichophyton rubrum a 15 días en agar Lactrimel a $37^{\circ} \mathrm{C}$.

detallados para establecer su clasificación (31). Si bien el número de géneros aumentó desde la tradicional clasificación de Emmons en 1934 (Trichophyton, Microsporum y Epidermophyton), las especies que son de importancia en el diagnóstico de rutina ahora pertenecen a grupos más pequeños lo cual mejora su identificación $(29,31)$. Otros hongos filamentosos no dermatofitos, considerados agentes etiológicos oportunistas, como Fusarium spp., Aspergillus spp., Scopulariopsis spp. y Acremonium spp., pueden ser causa de onicomicosis con una frecuencia estimada entre e 5 y $12 \%$ de los casos (32).

Dentro de las levaduras, el género Candida spp. es causa frecuente de dermatomicosis oportunista en piel, uñas y mucosas, debido principalmente al reservorio de algunas especies como
C. albicans, C. parapsilosis y $C$. tropicalis en pliegues cutáneos, cavidad oral, mucosa vaginal e intestinal. Malassezia spp. se relaciona principalmente con pitiriasis versicolor y en ocasiones a foliculitis. (30).

El diagnóstico de laboratorio de una micosis superficial comprende dos procesos: 1. examen microscópico directo, generalmente realizado con $\mathrm{KOH}$ al 20\% para detectar la presencia de elementos fúngicos mediante microscopia óptica, y 2. cultivos en agar sabouraud, lactrimel u otros medios selectivos para dermatofitos, incubados a 25 y $37^{\circ} \mathrm{C}$ durante dos a tres semanas. La identificación de los hongos filamentosos y levaduras se realiza en base a su morfofisiología. En los casos específicos de sospecha de pitiriasis versicolor, se emplea la técnica de muestreo con cinta adhesiva, 
tinción con safranina y observación microscópica directa, lo que permite el diagnóstico a nivel de género del complex Malassezia $(29,30)$. El rendi- miento del examen microscópico directo y el cultivo en el diagnóstico de micosis superficiales es del $85 \%$ aproximadamente (28).

\section{REFERENCIAS}

1. Cepero M, Restrepo S, Franco-Molado A, Cardenas M, Vargas N. Biología de los hongos. Ediciones Uniandes, Colombia. 2012.

2. Woese, C R \& Fox, G E. Phylogenetic structure of the prokaryotic domain: the primary kingdoms. Proc Nati Acad Sci USA. 1977; 74(11): 5088-90.

3. Piontelli E. Manual de microhongos filamentosos communes I. Tercera edición. Editorial particular. 2015.

4. Cruz R. Guía para el diagnóstico de laboratorio de enfermedad fúngica invasora por hongos filamentosos. Rev Chil Infectol. 2014; 31(2): 173-9.

5. Alburquenque $\mathbf{C}$, Tapia $\mathbf{C}$. Interacción Candida albicans-Hospedero: un proceso complejo en el que la inmunidad innata juega un importante papel. Bol Micol. 2013; 28(2):37-47.

6. Cruz R, Opazo H, Barthel E, Campos S, Piontelli E. Reporte clínico: histoplasmosis diseminada alóctona en un paciente con síndrome de inmunodeficiencia adquirida. Bol Micol. 2006; 21: 77-84.

7. Giusiano G, Piontelli E. Hongos oportunistas levaduriformes y filamentosos comunes en clínica. 1a ed. Resistencia: Editorial independiente; 2016.

8. Deacon, J. Fungal Biology. 4ta edición. Blackwell publishing, MA, E.U. 2006.

9. Moore-Landecker, E. Fundamentals of fungi. 4th ed. Prentice Hall, New Jersey, EU. 1996.

10. Acuña L G. Evolución de la terapia antimicrobiana: lo que era, lo que es y lo que será. Rev Chil Infect. 2003;20(Supl 1):7-10.
11. Andraca Perera JR, Rodríguez Gil E, Fundora Santana A. Cefalosporinas. Rev Cuba Farm. 2001;35(3):219-24.

12. de Llanos R, Fernández-Espinar MT, Querol A. A comparison of clinical and food Saccharomyces cerevisiae isolates on the basis of potential virulence factors. Antonie Van Leeuwenhoek. 2006; 90(3):221-31.

13. Le Dréan G, Mounier J, Vasseur V, Arzur D, Habrylo O, Barbier G. Quantification of Penicillium camemberti and $P$. roqueforti mycelium by real-time PCR to assess their growth dynamics during ripening cheese. Int J Food Microbiol. 2010; 31(138):100-07.

14. Noda Y. Las Micorrizas: Una alternativa de fertilización ecológica en los pastos. Pastos y Forrajes. 2009; 32(2): 1-10.

15. Chanagá $X$, Plácido J, Marín M, Yepres MDS. Hongos Nativos con Potencial Degradador de Tintes Industriales en el Valle de Aburrá , Colombia. Rev Fac Nac Agron Medellín. 2012;65(2):6811-21.

16. Bebber DP, Holmes T \& Gurr SJ. The global spread of crop pests and pathogens. Global Ecol. Biogeogr. 2014; 23: 1398-407.

17. Agarwal-Jans Sh. Emerging fungi threaten crop security, biodiversity and human health. So why are we looking the other way?. The silent invasion of the killer fungus. Elsevier. 2018.

18. Asamblea General NU. Informe del grupo de trabajo intergubernamental de expertos de compo- 
sición abierta sobre los indicadores y la terminología relacionados con la reducción del riesgo de desastres. Septuagésimo primer período de sesiones Tema 19c del programa Desarrollo sostenible: reducción del riesgo de desastres. 2016.

19. Fisher MC, Henk DA, Briggs CJ, Brownstein JS, Madoff LC, McCraw SL. Emerging fungal threats to animal, plant and ecosystem health. Nature. 2012; 484: 186-94.

20. Savary S, Bregaglio S, Willocquet L, Gustafson D, Mason D, D'Croz. Crop health and its global impacts on the components of food security. Food Sec. 2017; 9:311-27.

21. Kröner A, Mabon R, Corbière R, Montarry $\mathbf{J}$ \& Andrivon D. The coexistence of generalist and specialist clonal lineages in natural populations of the Irish Famine pathogen Phytophthora infestans explains local adaptation to potato and tomato. Molecular Ecology. 2017; 26: 1891-901.

22. Windels CE. Economic and social impacts of Fusarium Head Blight: changing farms and rural communities in the northern Great Plains. Phytopathology. 2000; 90(1):17-21.

23. Bailey BA, Evans HC, Phillips-Mora W, Ali SS, Meinhardt LW. Moniliophthora roreri, causal agent of cacao frosty pod rot. Molecular plant pathology. 2018; 19(7): 1580-94.

24. Nalley L, Tsiboe F, Durand-Morat A, Shew A \& Thoma G. Economic and Environmental Impact of Rice Blast Pathogen (Magnaporthe oryzae) Alleviation in the United States PLoS One. 2016; 11(12): e0167295.
25. Van Drunen SG, McCune JL, Husband BC. Distribution and environmental correlates of fungal infection and host tree health in the endangered American chestnut in Canada. Forest Ecology and Management. 2018; 427:60-69.

26. Berkeley.edu [Internet]. California: UC Berkeley Forest Pathology and Mycology Lab; [actualizado 24 Ago 2014; citado 07 Ene 2019]. Disponible en: https://nature.berkeley.edu/ matteolab/?p=1029

27. Zaror L, Collado L, Bohle H, Landskron , Montaña J, Avendaño F. Saprolegnia parasitica en salmones y truchas del sur de Chile. Arch Med Vet. 2004; 36(1):71-78.

28. Cruz R, Ponce E, Calderón L, Delgado N, Vieille P, Piontelli E. Micosis superficiales en la ciudad de Valparaíso, Chile. Período 2007-2009. Rev Chil Infect. 2011;28(5): 404-09.

29. Arenas R. Micosis superficiales. In: Arenas R, editor. Micología Médica Ilustrada. México McGrawHill. 2008.

30. Vilata JJ. Micosis Cutáneas. España: Panamericana. 2006.

31. de Hoog GS, Dukik K, Monod M, Packeu A, Stubbe D, Hendrickx M, et al. Toward a Novel Multilocus Phylogenetic Taxonomy for the Dermatophytes. Mycopathologia. 2017;182(1-2):5-31.

32. Relloso S, Arechavala A, Guelfand L, Maldonado I, Walker L, Agorio I, et al. Onicomicosis: estudio multicentrico clinico, epidemiologico y micologico.. Rev Iberoam Micol. 2012;29(3):15763. 